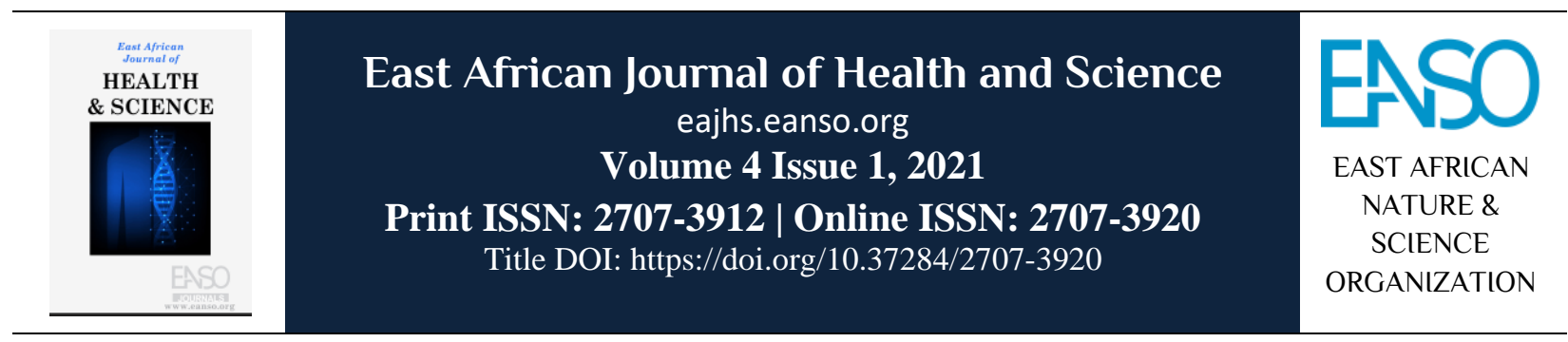

Original Article

\title{
Assessment of Factors Contributing to Delayed Surgeries in Enlarged Prostate Patients: A Survey at Kisumu County Referral Hospital.
}

\author{
Lucy Natecho Namusonge $(\text { RN/MPH })^{1}$ \& Jacob Odhiambo Ngachra (RN/CRNA $)^{2}$. \\ ${ }^{1}$ Kibabii University, P. O. Box 2008-50200 Bungoma, Kenya. \\ ${ }^{2}$ Muhoroni County Hospital, P. O. Box: 486-40100 Kisumu-Kenya. \\ *Author for correspondence ORCID ID: https://orcid.org/0000-0003-1189-1171, email: jacoodhiambo78@ gmail.com.
}

Article DOI: https://doi.org/10.37284/eajhs.4.1.447

\section{Date Published: ABSTRACT}

26 October 2021 Enlarged prostate, also known as Benign Prostatic Hyperplasia (BPH) is the enlargement of the prostate gland in men resulting in frequent urination, weak Keywords: urine stream, and inability to completely empty the bladder. Prostate cancer

Enlarged Prostate,

Benign Prostate

Hyperplasia,

Surgery,

Transurethral Resection

of The Prostate,

Spinal Anaesthesia,

Surgical Outpatient

Clinic,

Level of Knowledge,

Awareness,

Factors Leading to

Delayed Surgeries. is the second most commonly occurring cancer in men and the fourth most commonly occurring cancer overall. There were 1.3 million new cases of prostate cancer globally in 2018. Although there is a scarcity of information on the disease in African men, past studies have revealed that the disease can be managed if detected in its early stages. The purpose of the study was to assess the factors contributing to delayed surgeries in enlarged prostate patients at Kisumu County Referral hospital. Specific objectives were to determine the level of knowledge and awareness on enlarged prostate; assess institutional factors hindering surgeries in enlarged prostate and determine socio-economic factors of the patients' hindering surgeries in enlarged prostate at Kisumu County Referral hospital. A descriptive survey design was adopted for the study. The study targeted enlarged prostate patients and top management of the Kisumu County Referral Hospital from which a sample of 50 respondents was selected using the inclusion-exclusion criteria to participate in the study. The study adopted structured questionnaires for data collection. Data were analysed using descriptive statistics with both qualitative and quantitative analysis and the findings were presented in frequency distribution tables and percentages. The study achieved a questionnaire return rate of $94 \%$ with the majority of the respondents, $45 \%$, earning a monthly income ranging from 10,000 to 20,000 . Findings revealed that $91 \%$, had knowledge of prostate cancer with $83 \%$ stating that the medium through which they learned of the disease was the media, friends, relatives,

24 | This work is licensed under a Creative Commons Attribution 4.0 International License. 
and at the workplace. Unwillingness to be screened for prostate cancer was due to a lack of knowledge (53\%). The study established the hospital was crowded, $78 \%$, and thus the available resources were not sufficient to cater to the population seeking medical attention. Institutional factors related to doctors'/nurses' workmanship were the common contributors to delayed surgeries and medical attention in terms of negligence, 66\%, poor communication channels hence conflicting information, $72 \%$, and doctors'/nurses' competence at work, 42\%. Evidently, the family plays a major role in one's health decisions especially pertaining to chronic diseases such as cancer, $66 \%$. Lack of finances limits access to quality and timely healthcare with $83 \%$ and $87 \%$ respectively. Conclusively, the majority of the delays in surgeries in enlarged prostate patients at the hospital were due to the institution's inability in terms of resources, facilities, and qualified and competent personnel. Socio-economic factors also contributed to delayed surgeries in enlarged prostate patients at Kisumu County Referral Hospital. The study recommends mobilization and sensitization to create awareness and increase the knowledge of prostate cancer, the government should intervene through improving the facilities, resources, and staff as a measure to manage the ever-increasing population seeking medical care at the hospital and to find ways of reducing medical costs, especially for cancer patients, so as to enable victims' access medical care with ease.

\section{APA CITATION}

Namusonge, L. N., \& Ngachra, J. O. (2021). Assessment of Factors Contributing to Delayed Surgeries in Enlarged Prostate Patients: A Survey at Kisumu County Referral Hospital. East African Journal of Health and Science, 4(1), 24-40. https://doi.org/10.37284/eajhs.4.1.447.

\section{CHICAGO CITATION}

Namusonge, Lucy Natecho, \& Jacob Odhiambo Ngachra. 2021. "Assessment of Factors Contributing to Delayed Surgeries in Enlarged Prostate Patients: A Survey at Kisumu County Referral Hospital.”. East African Journal of Health and Science 4 (1), 24-40. https://doi.org/10.37284/eajhs.4.1.447.

\section{HARVARD CITATION}

Namusonge, L. N., \& Ngachra, J. O. (2021) "Assessment of Factors Contributing to Delayed Surgeries in Enlarged Prostate Patients: A Survey at Kisumu County Referral Hospital.”, East African Journal of Health and Science, 4(1), pp. 24-40. doi: 10.37284/eajhs.4.1.447.

\section{IEEE CITATION}

L. N. Namusonge, \& J. O. Ngachra, "Assessment of Factors Contributing to Delayed Surgeries in Enlarged Prostate Patients: A Survey at Kisumu County Referral Hospital.”, EAJHS, vol. 4, no. 1, pp. 24-40, Oct. 2021.

\section{MLA CITATION}

Namusonge, Lucy Natecho, \& Jacob Odhiambo Ngachra. "Assessment of Factors Contributing to Delayed Surgeries in Enlarged Prostate Patients: A Survey at Kisumu County Referral Hospital.”. East African Journal of Health and Science, Vol. 4, no. 1, Oct. 2021, pp. 24-40, doi:10.37284/eajhs.4.1.447.

\section{INTRODUCTION}

Prostate cancer (PC), an adenocarcinoma of the male prostate gland, has in the recent past become an important health burden among men in the world (Ferlay et al., 2011; Lozano et al., 2012). An estimated 0.9 million cases and 0.26 million deaths of prostate cancer occur annually in the world (Ferlay et al., 2011). Prostate cancer is the number one cancer in both incidences and mortality in Africa, constituting 40,000 (13\%) of all male cancer incidences and 28,000 (11.3\%) of all male cancer- 
associated mortalities (Ferlay et al., 2011). In East Africa, prostate cancer ranks third in both incidence and mortality and leads to an estimated 9,000 (9\% of all male cancers) cases and 7,300 (8.5\% of all male cancer) deaths annually (Ferlay et al., 2011). It is important to note that PC incidences increased by $64.5 \%$ between 1990 and 2010 (Lozano et al., 2012).

Prostate cancer has been on the rise in the recent past despite various attempts to contain the condition. Sigrid (2010) observes that treatment of PC is possible when detected in its early stages, that is when the disease is still localized in the prostate. There are a number of ways through which prostate cancer can be treated and these include screening at the stage of development of the disease when there are no symptoms to reduce the possibility of developing the disease at the asymptomatic stage as evidenced in breast and cervical cancer in females. However, screening in prostate cancer involves physical examination to palpate the prostate by digital rectal examination (DRE), by measuring the levels of prostate-specific antigen (PSA) in the blood or by biopsy in which a sample of prostate gland tissue is taken for histological examination (IARC, 2018).

According to Negoita et al., (2018), many men with prostate cancer never have symptoms and unless they undergo screening or expensive signs associated with the later stages, they may never know they have the disease. In the United States, for instance, the lifetime risk of being diagnosed with prostate cancer is approximately $11 \%$ and the lifetime risk of dying from prostate cancer is $2.5 \%$ (Negoita et al., 2018). Jemal et al., (2010) noted that African American men have the highest incidences of prostate cancer worldwide and are likely to develop the disease at any age and develop the disease earlier in life than men from all other racial and ethnic groups. This finding may be an indication that prostate cancer is more prevalent among black men than any other race.

In its 2018 PC screening recommendations, the USPSTF reported that there exists adequate evidence from randomized clinical trials documenting that PSA-based screening in men aged

facilities is acquired. Public hospitals are mainly funded by the Government of Kenya with minimal
55-69 years might prevent approximately 1.3 deaths from PC over approximately 13 years per 1,000 men screened. The evidence illustrated that screening programs might also prevent approximately 3 cases of metastatic PC per 1,000 men screened (Cheuck L, et al., 2018).

In Africa, as reported by Ferlay et al., (2011), 0.9 million cases and 0.26 million deaths of prostate cancer occur annually. PC is leading cancer in both incidence and mortality in Africa contributing to $13 \%$ of the entire male cancer incidence and $11.3 \%$ of all male cancer-associated mortalities. It has been reported that PC is the leading type of cancer in both incidence and mortality in men from Africa and the Caribbean (IARC, 2014). It is further noted that PC is a growing problem in Africa with approximately 28,000 deaths from PC in 2010 and approximately 60,000 deaths projected by 2030 if aggressive interventions are not put in place. This implies that there could be a lack of early presenting symptoms resulting in patients being diagnosed with advanced disease where the emphasis is on palliative treatment and supportive care.

According to MPHS and MMS (2011), most patients in Kenya present with advanced disease due to low awareness and lack of early screening services. A number of studies carried out in various health facilities in the country, Kenyatta National Hospital included, have reported that most prostate cancer patients report to hospital with advanced disease but their awareness and knowledge levels of prostate cancer are undefined. The health sector in Kenya, through the National Reproductive Health Policy, 2007 and the National Reproductive Health Strategy, 2009-2015 provide the policy framework, with cancers of the reproductive organs being priority components. Despite this favourable policy and efforts towards enhancing PC screening, existing data still shows that Prostate Cancer is diagnosed when it's already in its advanced stages among Kenyan men. This has been aggravated by the fact that PC screening is not a common practice and patients go for it when the disease is quite advanced.

The Kenyan healthcare system can be categorized into three in relation to where the funding for the

input from co-pay by the patients. Previous experience in these facilities revealed a slow pace of 
service delivery in public hospitals which was not witnessed in other categories of the hospitals. A delay in offering services, frequent disputes between management and staff in relation to delayed payment of dues, inadequate working equipment, and poor working environment formed part of disruptions of service delivery. These disruptions were not witnessed in private facilities as their operations were smoother and the process from admission to discharge had very minimal disruptions (Minja, 2017). The researcher was motivated by this finding to find out the cause for this disparity. With the case of Kisumu County Referral Hospital, a public hospital, the researcher set to assess the factors contributing to delayed surgeries in Enlarged Prostate at the hospital.

\section{Objectives of the Study}

The broad objective of the study was to assess the factors contributing to delayed surgeries in enlarged prostate patients at Kisumu County Referral Hospital. The specific objectives were to: assess how the level of knowledge and awareness leads to delayed surgeries in enlarged prostate patients at Kisumu County Referral Hospital; assess how institutional factors contribute to delayed surgeries in enlarged prostate patients at Kisumu County Referral Hospital; and assess the socio-economic factors contributing to delayed surgeries in enlarged prostate patients at Kisumu County Referral Hospital.

\section{CONCEPTUAL FRAMEWORK}

\section{Aspects pf PC}

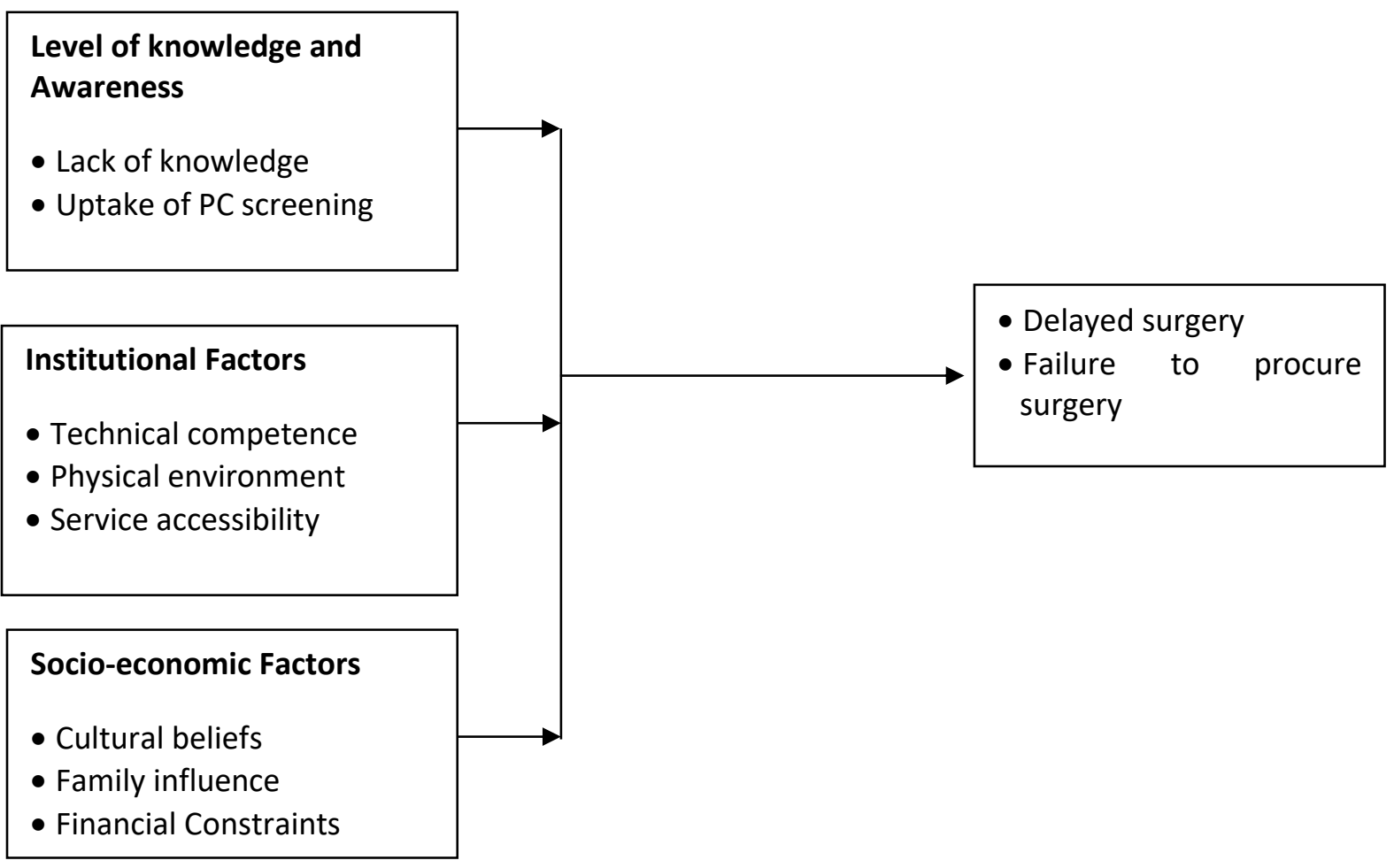

Independent Variables

Dependent Variable 


\section{MATERIALS AND METHODS}

\section{Research Design}

The study adopted a descriptive survey research design with both qualitative and quantitative approaches. Descriptive survey design is a method of collecting information by interviewing or administering questionnaires to a sample of individuals hence suitable for extensive research. It is an excellent vehicle for the measurement of characteristics of a large population (Orodho, 2003). Further, this method was preferred for the study as it maintains a high level of confidentiality; is convenient and enables data to be collected faster, enables questions to be asked personally in an interview, or impersonal through a questionnaire about things that cannot be observed easily. It also allows a researcher an opportunity to get an accurate view of response to issues as well as test theories on the social relationships at both the individual and group level (Kothari, 2003). The descriptive design also allows for the collection and analysis of both qualitative and quantitative data.

Quantitatively, the study utilised close-ended sections of the questionnaires to collect data on the subject of study while on the qualitative side, the study utilised interviews and the open-ended sections of the questionnaire to collect data on the same parameters.

\section{Study Area}

The study was conducted at Kisumu County Referral Hospital. The hospital has a capacity of approximately 800 beds with $100 \%$ bed occupancy. The study was conducted in surgical outpatients' clinic, operation theatre, and outpatient accident and emergency departments.

\section{Target Population}

The target population comprised of patients at Kisumu County Referral Hospital in the Male Surgical Unit, theatre, outpatient accident, and emergency departments, doctors/nurses in the surgical departments, and the management of the hospital.

\section{Sampling Procedure and Sample Size}

A sample size of 50 respondents was selected from the target population using simple random sampling putting into consideration the inclusion and exclusion criteria. On the part of inclusion, all consenting enlarged prostate patients were eligible for the study, doctors/nurses in the surgical departments were also eligible for the study. The top management of the hospital was also included in the study. On the other part, exclusion criteria were used to eliminate from the study patients who were not suffering from an enlarged prostate and nonconsenting enlarged prostate patients.

\section{Research Instrument}

The data collection instruments for this study were questionnaires and interview. Questionnaires as defined by Saunders et al., (2013) are all techniques of data collection in which each person is asked to respond to the same set of questions in a predetermined order. In this case, questionnaires were personally administered by the researcher and the research assistant to the respondents. According to Sekaran (2006) personally administered questionnaires enables the researcher to make clarifications when necessary and normally results in higher rates of return.

\section{Data Collection Methods}

The study adopted a structured questionnaire to collect data from the respondents. The study also relied on secondary data obtained from books, journals, websites and health records. Additional information was also obtained through observation of the behaviour of the population under study as it occurred without any manipulation by the researcher.

\section{Data Analysis and Presentation}

Descriptive statistics were used to analyse the research data and the analysis was guided by the objectives of the study. All the analysis was done using statistical package for social sciences (SPSS v. 25.0). Descriptive statistics were presented in graphs, tables, frequencies and numerations. Qualitative data was analysed thematically. 
East African Journal of Health and Science, Volume 4, Issue 1, 2021

Article DOI: https://doi.org/10.37284/eajhs.4.1.447

\section{RESULTS}

\section{Response Rate and Questionnaire Return Rate}

The study targeted all enlarged prostate patients at Kisumu County Referral Hospital from which a sample of 50 respondents was selected to participate in the study. Questionnaires were distributed to the respondents to which they responded and returned. Of the 50 questionnaires distributed, 47 (94\%) were returned in time to allow for the analysis of the data. However, $3(6 \%)$ of the distributed questionnaires were not returned.

\section{Demographic Information of the Respondents}

The study established that the majority of the respondents $(40(86 \%)$ were in the age bracket 43 and above years. Of the respondents, $3(6 \%)$ were in the age bracket $33-42$ years; $2(4 \%)$ were in age rackets 28-32 and 18-27 years respectively (Table 1). This finding is in agreement with that of Jemal et al., (2018) who noted that African men have the highest incidences of prostate cancer worldwide and are likely to develop the disease at any age and develop the disease earlier in life than men from all other racial and ethnic groups.

Study findings revealed that majority of the respondents, 19 (40\%) had no formal education some of which had only elementary technical skills in various fields. Of the respondents $16(34 \%)$ had attained primary education while $8(17 \%)$ had secondary education. University education had the least representation with only $4(9 \%)$ of the respondents falling in this category. The study therefore, received responses from patients of different academic qualifications.

The study findings indicate that majority of the respondents, 21 (45\%) were employed casually on a daily or contractual basis followed by the selfemployed respondents with a representation of 13 $(28 \%)$. Of the respondents, 8 (17\%) were permanently employed while $5(11 \%)$ were not actively engaged in any income-generating activities. It was also noted that majority of the respondents, $21(45 \%)$ earned a monthly income of between Kshs. 11,000 - 20,000 followed by those who earned between Kshs. 21,000-30,000 with a representation of $11(23 \%)$. Of the respondents, 8 (17\%) earned less than Kshs. 10,000, 5 (11\%) earned between Kshs. 31,000-40,000 while only 2 (4\%) of the respondents earned Kshs. 41,000 and above (Table 1).

Majority of the respondents, 21 (45\%) had started chemotherapy sessions followed by $12(26 \%)$ who had started radiotherapy sessions. Of the respondents, $8(17 \%)$ respondents had not started treatment sessions while only $6(13 \%)$ were on follow-up after treatment sessions (Table 1).

It was also established that the respondents had been suffering from prostate cancer for varying period of between $1-12$ years. The study also established that some of the respondents were not sure of when they started suffering from the disease and hence could not establish the exact period for which they had been sick of the disease. 
East African Journal of Health and Science, Volume 4, Issue 1, 2021

Article DOI: https://doi.org/10.37284/eajhs.4.1.447

Table 1: Demographic Information of Respondents

\begin{tabular}{|c|c|c|c|}
\hline \multicolumn{2}{|l|}{ Demographic Factor } & \multirow{2}{*}{$\frac{\text { Frequency }}{2}$} & \multirow{2}{*}{$\begin{array}{l}\text { Percentage (\%) } \\
4 \%\end{array}$} \\
\hline Age & $18-27$ & & \\
\hline & $28-32$ & 2 & $4 \%$ \\
\hline & $33-42$ & 3 & $6 \%$ \\
\hline & 43 - and above & 40 & $86 \%$ \\
\hline & Total & 47 & 100 \\
\hline \multirow[t]{5}{*}{ Level of Education } & Primary & 16 & $34 \%$ \\
\hline & Secondary & 8 & $17 \%$ \\
\hline & University & 4 & $9 \%$ \\
\hline & Others & 19 & $40 \%$ \\
\hline & Total & 47 & 100 \\
\hline \multirow[t]{5}{*}{ Occupation } & Casual & 21 & $45 \%$ \\
\hline & Permanently Employed & 8 & $17 \%$ \\
\hline & Self-employed & 13 & $28 \%$ \\
\hline & Not employed & 5 & $11 \%$ \\
\hline & Total & 47 & $100 \%$ \\
\hline \multirow[t]{6}{*}{ Income level } & Less than 10,000 & 8 & $17 \%$ \\
\hline & $11,000-20,000$ & 21 & $45 \%$ \\
\hline & $21,000-30,000$ & 11 & $23 \%$ \\
\hline & $31,000-40,000$ & 5 & $11 \%$ \\
\hline & $41,000-$ and above & 2 & $4 \%$ \\
\hline & Total & 47 & $100 \%$ \\
\hline \multirow[t]{5}{*}{ Stage of Treatment } & Not started treatment sessions & 8 & $17 \%$ \\
\hline & Started radiotherapy sessions & 12 & $26 \%$ \\
\hline & Started chemotherapy sessions & 21 & $45 \%$ \\
\hline & Follow up after treatment sessions & 6 & $13 \%$ \\
\hline & Total & 47 & $100 \%$ \\
\hline
\end{tabular}

\section{Level Knowledge and Awareness of Prostate Cancer}

The study, in its first objective intended to assess the level of knowledge and awareness of prostate cancer among the enlarged prostate patients at Kisumu County Referral Hospital. The findings of the study on the same are presented in this section.

\section{Meaning of and Risks of Prostate Cancer}

The study sought to ascertain whether or not the respondents were familiar with prostate cancer and the findings are presented in Table 2. The study established that the majority of the respondents 43 $(91 \%)$ had heard of prostate cancer while only 4 (9\%) reported that they had no knowledge of prostate cancer at all (Table 2). The respondents were also asked to state the medium/ means through which they had received news about prostate cancer. The study findings indicated that the most common source of information cited for relaying information on prostate cancer were electronic media (radio/TV) and the print media with $39(83 \%)$ of the respondents affirming to this this. Other sources of information cited were friends and relatives. The study also established that hospitals, doctors and pharmacies were the least common in the list as a source of information on prostate cancer with only $4(9 \%)$ of the respondents positively affirming these. These findings by the current study are in line with the findings of an earlier study by Oladepo et al., (2009) who reported that sources of information on prostate cancer were majorly friends, relatives, workplace and the media, both electronic and printed. 
The respondents were also asked to state their view on whether or not they were at a high risk of contracting prostate cancer and the results of the same are summed up in Table 2 . The study findings in Table 2 reveal that majority of the respondents 26 $(55 \%)$ believed that they were at a high risk of getting prostate cancer while $8(17 \%)$ held the opinion that they were not at a high risk of getting the disease. Of the respondents, $13(28 \%)$ were not sure whether or not they were at a high risk of getting prostate cancer. This finding is in line with that of a previous study by Mutua et al., (2017) which found that it was widely believed that men aged over 40 years are at a high risk of getting prostate cancer.

Table 2: Meaning and View on Risk of Getting Prostate Cancer

\begin{tabular}{lll}
\hline Response & Frequency & Percentage (\%) \\
\hline Meaning of Prostate Cancer & & \\
\hline Yes & 43 & $91 \%$ \\
No & 4 & $9 \%$ \\
Total & $\mathbf{4 7}$ & $\mathbf{1 0 0 \%}$ \\
\hline View on Risk of Getting Prostate Cancer & $55 \%$ \\
\hline Yes & 26 & $17 \%$ \\
No & 8 & $28 \%$ \\
Not sure & 13 & $\mathbf{1 0 0 \%}$ \\
Total & $\mathbf{4 7}$ & \\
\hline
\end{tabular}

\section{Methods and Frequency of Screening Prostate Cancer}

Moreover, the study sought to ascertain whether or not the respondents were aware of the methods used for screening prostate cancer. As such, the respondents were asked to state the method that was used to screen them for the disease and the findings are as shown in Table 3. As revealed by the results presented in Table 3, it is evident that majority of the respondents had no knowledge on the methods of prostate cancer screening with $18(38 \%)$ of the respondents positively affirming this. Findings also indicated the biopsy was a common method used to screen for cancer with 13 (28\%) of the respondents affirming this. Prostate specific antigen (PSA) was the least common method of screening with only 7 $(15 \%)$ of the respondents stating that this was the method that they used while being screened for the disease.

As regards how often one should be screened for prostate cancer, the findings of the study are presented in Table 3. It was established from the study findings that majority of the respondents didn't know how often one should be screened for prostate cancer with $32(68 \%)$ of the respondents positively confirming this. The respondents were also asked to give their view on what hinders people from being screened for prostate cancer and the study findings are as shown in Table 3. 
East African Journal of Health and Science, Volume 4, Issue 1, 2021

Article DOI: https://doi.org/10.37284/eajhs.4.1.447

Table 3: Methods and Frequency of Screening Prostate Cancer

\begin{tabular}{lll}
\hline Response & Frequency & Percentage (\%) \\
\hline Method for Screening Prostate Cancer & & \\
\hline Prostate specific antigen (PSA) & 7 & $15 \%$ \\
Digital Rectal Examination (DRE) & 9 & $19 \%$ \\
Biopsy & 13 & $28 \%$ \\
I do not know & 18 & $38 \%$ \\
Total & 47 & $100 \%$ \\
\hline Frequency of Prostate Cancer Screening & & \\
\hline Yearly & 9 & $19 \%$ \\
Every two years & 4 & $9 \%$ \\
Every three years & 2 & $4 \%$ \\
I do not know & 32 & $68 \%$ \\
Total & $\mathbf{4 7}$ & $\mathbf{1 0 0 \%}$ \\
\hline
\end{tabular}

Hindrance to and Knowledge on Signs and Symptoms of Prostate Cancer

The respondents were also asked to give their view on what hinders people from being screened for prostate cancer and the findings are as shown in Table 4. The study established that most the major hindrance to prostate cancer screening was lack of knowledge with $25(53 \%)$ of the respondents affirming this. Ignorance (deliberately unwilling to know) was not cite as a major hindrance as only 3 (6\%) of the respondents agreeing to it as being a hindrance. It was also established that fear of the unknown and possibly the feeling that one may test positive and have to live with the condition also came up as a hindrance with 13 (28\%) of the respondents confirming this.

In order to ascertain whether or not the respondents were aware of the signs and symptoms of prostate cancer, the study sought the views of the respondents on the same. The respondents were to tell whether or not a man may have prostate cancer without any pain or symptoms and the findings are as shown in Table 4.

The majority of the respondents $27(57 \%)$ reported that a man may have cancer without any pain or

symptoms while $17(36 \%)$ of the respondents refuted the same. Of the respondents, $3(6 \%)$ were not sure whether or not one could have prostate cancer without pain or symptoms. This finding is in agreement with that of Negoita et al., (2018) who reported that many men with prostate cancer never have symptoms and unless they undergo screening or expensive signs associated with the later stages, they many never know they have the disease. The study also sought to find out the views of the respondents on the issue that prostate cancer is anyone who gets it no matter when it is found and how it is treated. An analysis of the findings revealed that the majority of the respondents 29 (62\%) strongly agreed with the statement while only $4(9 \%)$ of the respondents were not sure. Of the respondents $14(30 \%)$ strongly disagreed (Table 4). This is an indication that it is widely held that prostate cancer is a killer disease and no matter the stage of its detection and medical intervention, it cannot be reversed.

Moreover, the study interrogated the respondents to give some of the risk factors of prostate cancer. Some of the factors highlighted included early sexual engagement, multiple sexual partners, poor diet, family history, lack of physical exercise, and carbonated drinks. 
East African Journal of Health and Science, Volume 4, Issue 1, 2021

Article DOI: https://doi.org/10.37284/eajhs.4.1.447

Table 4: Hinderance to and Knowledge on Signs and Symptoms of Prostate Cancer

\begin{tabular}{lll}
\hline Response & Frequency & Percentage (\%) \\
\hline Hindrance to Prostate Cancer Screening & & \\
\hline Lack of knowledge & 25 & $53 \%$ \\
Fear of the unknown & 13 & $28 \%$ \\
Ignorance (deliberately unwilling to know) & 3 & $6 \%$ \\
I do not know & 6 & $13 \%$ \\
Total & $\mathbf{4 7}$ & $\mathbf{1 0 0 \%}$ \\
\hline Knowledge on Signs and Symptoms of Prostate Cancer & & \\
\hline True & 27 & $57 \%$ \\
False & 17 & $36 \%$ \\
Not sure & 3 & $6 \%$ \\
Total & $\mathbf{4 7}$ & $\mathbf{1 0 0 \%}$ \\
\hline
\end{tabular}

\section{Institutional Factors Contributing to Delayed Surgeries}

The second objective of the study was to assess how institutional factors contribute to delayed surgeries in enlarged prostate patients at Kisumu County Referral Hospital. To achieve this, the respondents were asked a series of questions on the link between various institutional factors and delayed surgeries among enlarged prostate patients and the findings are presented in the subsequent sub-sections of this section.

\section{Population of the Hospital}

The study intended to establish the population of the hospital against the available hospital resources. To achieve this, the respondents were asked to rate, on a specific scale, the extent to which they agreed or disagreed with the statement that the hospital is overcrowded and the study findings are presented in Table 5.

Research findings indicated that the majority of the respondents $25(53 \%)$ strongly agreed that the hospital was overcrowded while $13(28 \%)$ of the respondents agreed with the statement. Of the respondents, $6(13 \%)$ disagreed with the statement while $3(6 \%)$ remained neutral on the matter. None of the respondents strongly disagreed that the hospital was crowded. It can be deduced from these findings that the hospital under review is crowded and it is thus most likely that the number of patients seeking medical services at the facility far outweigh its resource capacity and facilities; a likely causative factor for delayed attention from the doctors to the patients.

Table 5: Population of the Hospital

\begin{tabular}{|c|c|c|c|c|c|c|c|c|c|c|}
\hline \multirow[t]{3}{*}{ Statement } & \multicolumn{10}{|c|}{ Responses (\%) } \\
\hline & $\mathbf{f}$ & $\%$ & $\mathbf{f}$ & $\%$ & $\mathbf{f}$ & $\%$ & f & $\%$ & $\mathbf{f}$ & $\%$ \\
\hline & 4 & & 3 & & $\mathbf{0}$ & & 2 & & $\mathbf{1}$ & \\
\hline The hospital is crowded & 25 & 53 & 13 & 28 & 3 & 6 & 6 & 13 & 0 & 0 \\
\hline
\end{tabular}

Key: 4 = Strongly Agree, 3 = Agree, $0=$ Neutral, 2 = Disagree 1=Strongly Disagree, F=Frequency

\section{Cleanliness of the Hospital}

The study sought the views of the respondents on the level of cleanliness and hygiene in the hospital and the findings are as presented in Table 6. The study findings indicate that cleanliness in the hospital is not highly maintained with $24(51 \%)$ of the respondents disagreeing and 7 (15\%) strongly disagreeing with the statement. However, 9 (19\%) agreed while $3(6 \%)$ strongly agreed with the statement that cleanliness in the hospital was highly maintained. 
Table 6: Cleanliness in the Hospital

\begin{tabular}{|c|c|c|c|c|c|c|c|c|c|c|}
\hline \multirow[t]{3}{*}{ Statement } & \multicolumn{10}{|c|}{ Responses (\%) } \\
\hline & $\mathbf{f}$ & $\%$ & $\mathbf{f}$ & $\%$ & $\mathbf{f}$ & $\%$ & $\mathbf{f}$ & $\%$ & $\mathbf{f}$ & $\%$ \\
\hline & 4 & & 3 & & $\mathbf{0}$ & & 2 & & 1 & \\
\hline Cleanliness in the hospital is highly maintained & 3 & 6 & 9 & 19 & 4 & 9 & 24 & 51 & 7 & 15 \\
\hline
\end{tabular}

\section{Presence of Signs and Signages}

The respondents were asked to state the extent to which they agreed or disagreed with the ease at which one could get directions in the hospital due to the presence of signs and signages and the findings are summed up in Table 7. It is evident from the research data that the majority of the respondents, $17(36 \%)$ disagreed while 4(9\%) strongly disagreed with the statement that there were signages in the hospital. Of the respondents, 14 (30\%) agreed with the statement while $4(9 \%)$ strongly agreed with the statement. Notable in the findings was however the significant number of the respondents, $8(17 \%)$ who remained neutral on the matter. This finding may point out that first time visitors to the hospital may have to struggle to find directions to their respective service points.

The respondents were also requested to rate the conditions of the waiting areas in terms of cleanliness and conduciveness and the findings are presented in Table 7.

Table 7: Presence of Signs and Signages

\begin{tabular}{|c|c|c|c|c|c|c|c|c|c|c|}
\hline \multirow[t]{3}{*}{ Statement } & \multicolumn{10}{|c|}{ Responses (\%) } \\
\hline & $\mathbf{f}$ & $\%$ & f & $\%$ & $\mathbf{f}$ & $\%$ & $\mathbf{f}$ & $\%$ & $\mathbf{f}$ & $\%$ \\
\hline & 4 & & 3 & & 0 & & 2 & & 1 & \\
\hline $\begin{array}{l}\text { It is easy to find direction in the hospital due to } \\
\text { presence of signages }\end{array}$ & 4 & 9 & 14 & 30 & 8 & 17 & 17 & 36 & 4 & 9 \\
\hline
\end{tabular}

The respondents were also requested to rate the conditions of the waiting areas in terms of cleanliness and conduciveness and the findings were presented in Table 8. As indicated by the earlier findings of the study on the general cleanliness of the hospital, it also emerged that majority of the respondents were opposed to the statement that the waiting areas were clean and conducive with $22(45 \%)$ disagreeing and $5(11 \%)$ strongly disagreeing. Of the respondents, 11 (23\%) agreed while $5(11 \%)$ strongly agreed that the waiting areas in the hospital were clean and conducive.

Table 8: Cleanliness and Conduciveness of the Waiting Areas

\begin{tabular}{lllllllllll}
\hline Statement & \multicolumn{1}{l}{ Responses (\%) } & & & \\
\cline { 2 - 10 } & $\mathbf{f}$ & $\mathbf{\%}$ & $\mathbf{f}$ & $\mathbf{\%}$ & $\mathbf{f}$ & $\mathbf{\%}$ & $\mathbf{f}$ & $\mathbf{\%}$ & $\mathbf{f}$ & $\mathbf{\%}$ \\
\hline & $\mathbf{4}$ & & $\mathbf{3}$ & & $\mathbf{0}$ & & $\mathbf{2}$ & & $\mathbf{1}$ & \\
\hline The waiting areas are clean and conducive & 5 & 11 & 11 & 23 & 5 & 11 & 21 & 45 & 5 & 11 \\
\hline Key: $4=$ Strongly Agree, $3=$ Agree, $0=$ Neutral, & 2 Disagree $1=$ Strongly & Disagree, $F=$ Frequency
\end{tabular}

34 | This work is licensed under a Creative Commons Attribution 4.0 International License. 


\section{Other Institutional Factors Contributing to Delayed Surgeries}

The respondents were asked to rate the extent to which they agreed or disagreed with several institutional factors that may contribute to delayed surgeries and or medical care services and the study findings are summarized in Table 9.

Research findings in Table 9 revealed that factors related to doctors/nurses are the major contributors to delayed surgeries and medical services at the hospital under review. It was revealed by the majority of the respondents, $31(66 \%)$ strongly disagreeing that the doctors/nurses take enough care to check for everything when diagnosing or treating patients hence cases of misdiagnosis and inappropriate treatment interventions. The respondents also refuted claims that the doctors/nurses and offer clarifications to questions or situations not clear with $37(79 \%)$ of the respondents strongly disagreeing with the same.

As regards the matter of conflicting information being issued at the time by the hospital staff, 31 $(66 \%)$ of the respondents agreeing and $3(6 \%)$ strongly agreeing with the statement (Table 9).

The majority of the respondents also indicated patients are hardly notified of the likely side effects of medication with 29 (62\%) strongly disagreeing and $11(23 \%)$ disagreeing with the statement that patients are notified of the likely side effects of medication. A minimal $4(8 \%)$ of the respondents however indicated that patients are notified of the likely side effects of medication (Table 9).

In a previous study, Rashid and Jusoff (2009) noted that technical quality in health care services is defined primarily based on the technical accuracy of diagnoses or procedures as well as on compliance with professional specifications and that technical quality is mainly a function of competence of the personnel providing the service. It was discovered by the current study that the competence of some doctors/nurses was questionable with 18 (38\%) and $2(4 \%)$ of the respondents disagreeing and strongly disagreeing respectively with the statement that the doctors/nurses were well-trained and competent (Table 9). This is a factor that is likely to contribute to degraded and delayed medical care to the patients. A significant number of the respondents however indicated that the doctors/nurses were well trained and competent with $13(28 \%)$ and $11(23 \%)$ of the respondents either agreeing or strongly agreeing respectively.

As regards the issue of patients being treated with respect and their confidentiality is guaranteed, 26 $(55 \%)$ of the respondents were opposed to the statement and strongly disagreed while 7 (15\%) disagreed. Only 11 (23\%) of the respondents agreed with the statement (Table 9). This scenario may be attributed to the depletion of the resources and facilities due to the large number of patients that surpass the hospital capacity hence cases in which multiple patients have to share rooms and even beds.

As pertains to the involvement of patients in decision making about their treatment and care, findings of this study were in line with those of an earlier study by Omondi (2016) in which it was reported that management of the health care system in Kenya has generally been inefficient, incoherent and mostly driven by supply thus keeping the patients outside the design, development and implementation process. In this study, 32 (68\%) of the respondents strongly disagreed that they were involved in decision-making about their treatment and care.

Furthermore, the study established that accessibility to patients and chances of getting emergency treatment were low with $30(64 \%)$ of the respondents strongly disagreeing with the statement and $8(17 \%)$ disagreeing (Table 9). This is a major hindrance to quality care and may delay medical services to patients. This finding upholds that of Lodenyo et al., (2016) who observed that access to health care refers to the timely use of health services to achieve the best possible outcomes or the ease with which an individual can obtain needed medical services. Moreover, the study established even though appointments may be obtained right away on the first visit, there were questions regarding adherence to the same with $22(47 \%)$ strongly disagreeing and 9 (19\%) disagreeing. Of the respondents, $14(30 \%)$ indicated that appointments could be obtained right away on the first visit and are strictly adhered to (Table 9). 
Table 9: Other Institutional Factors Contributing to Delayed Surgeries

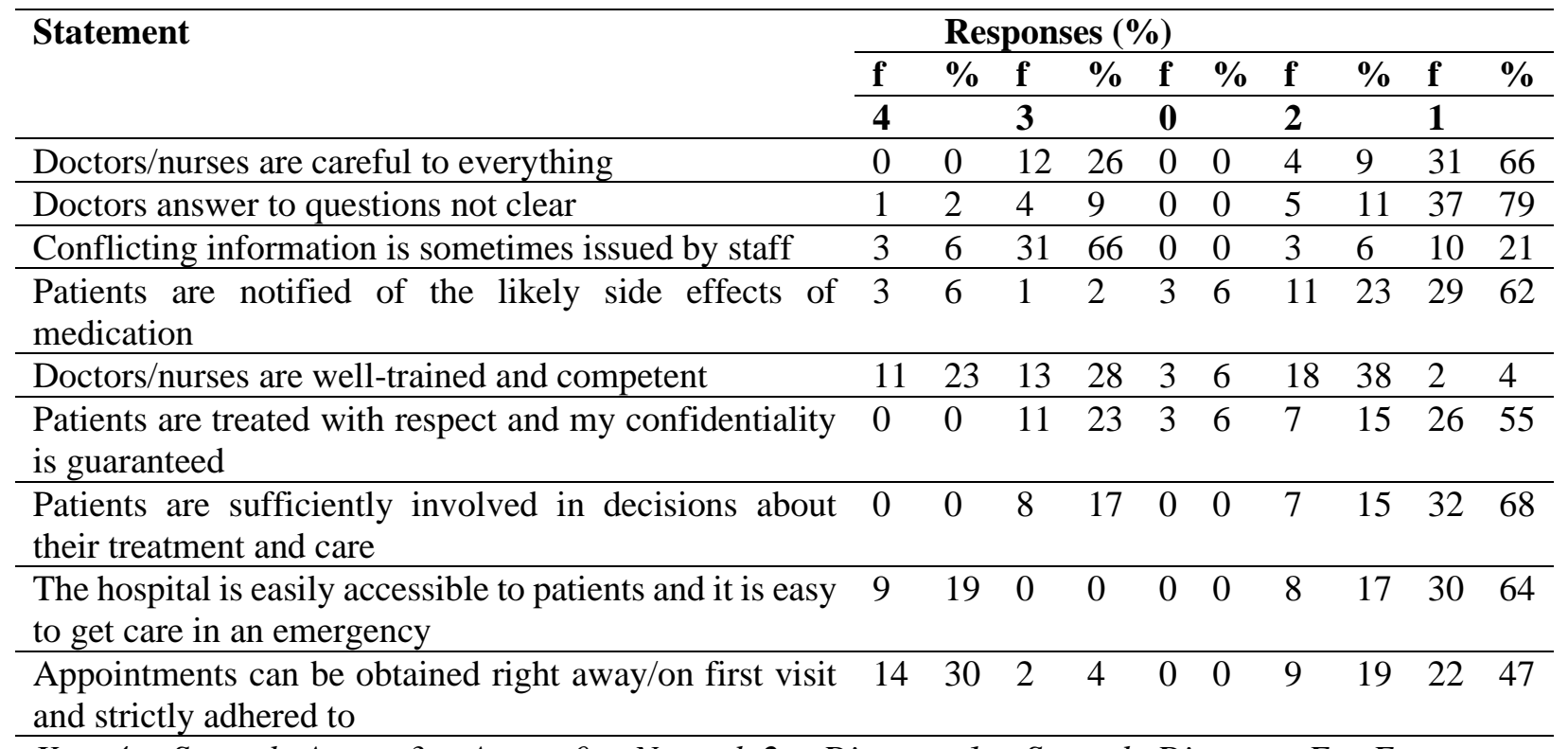

Key: 4 = Strongly Agree, $3=$ Agree, $0=$ Neutral, $2=$ Disagree $1=$ Strongly Disagree, $F=$ Frequency

\section{Socio-economic Factors Contributing to Delayed Surgeries}

The third objective of the study was to assess the socio-economic factors contributing to delayed surgeries in enlarged prostate patients at Kisumu County Referral Hospital.

To achieve this, the respondents were asked a series of questions on the link between various socioeconomic factors that are likely to influence medical services to patients and the findings are presented in Table 10.

The study findings presented in Table 10 reveal that the family plays a major role in one's health decisions especially pertaining to chronic diseases such as cancer with $66 \%$ of the respondents agreeing and $17 \%$ strongly agreeing. These findings are in agreement with Pinsky et al., (2017) who found that prostate cancer screening intent was best explained by pressure from the family or family influence. They linked familial influence in decision-making related to prostate cancer screening among African-American men.

The study also established that the majority of the respondents $21(45 \%)$ of the respondents agreed that traditional beliefs, myths and perceptions may hinder one's intent to seek medical services while 4
(9\%) of the respondents strongly agreed. However, $30 \%$ of the respondents were opposed to this statement and strongly disagreed there being any link between intent to seek medical service and traditional beliefs, myths and perceptions.

As earlier indicate by reports from the Ministry of Public Health and Sanitation (2011), the cost of treatment of cancer is enormous and many developing countries, such as Kenya, are unable to provide the systems necessary for this service and in the few cases where the service are available, they are few and far in between hence not accessible to the majority of the population. Relatively, as evident from the research findings, the economic status of an individual and lack of finances limits access to quality and timely healthcare with $83 \%$ and $87 \%$ of the respondents positively affirming these. It was also established that access to medical care may be limited by cultural beliefs with $57 \%$ of the respondents agreeing and $6 \%$ strongly agreeing with the statement. 
Table 10: Socio-economic Factors Contributing to Delayed Surgeries

\begin{tabular}{|c|c|c|c|c|c|c|c|c|c|c|}
\hline \multirow[t]{3}{*}{ Statement } & \multicolumn{10}{|c|}{ Responses (\%) } \\
\hline & $\mathbf{f}$ & $\%$ & f & $\%$ & $\mathbf{f}$ & $\%$ & $\mathbf{f}$ & $\%$ & $\mathbf{f}$ & $\%$ \\
\hline & 4 & & 3 & & $\mathbf{0}$ & & 2 & & 1 & \\
\hline $\begin{array}{l}\text { The family plays a major role on one's health decisions } \\
\text { especially for chronic diseases }\end{array}$ & 8 & 17 & 31 & 66 & 0 & 0 & 5 & 11 & 3 & 6 \\
\hline $\begin{array}{l}\text { Traditional beliefs/myths and perceptions may hinder } \\
\text { one's intent to seek medical services }\end{array}$ & 4 & 9 & 21 & 45 & 6 & 13 & 2 & 4 & 14 & 30 \\
\hline $\begin{array}{l}\text { The economic status of a person plays an important role } \\
\text { in their intent and ability to seek medical care }\end{array}$ & 5 & 11 & 39 & 83 & 1 & 2 & 2 & 4 & 0 & 0 \\
\hline Lack of finances limits access to quality health care & 5 & 11 & 41 & 87 & 1 & 2 & 0 & 0 & 0 & 0 \\
\hline $\begin{array}{l}\text { Access to medical care may be limited by cultural } \\
\text { beliefs }\end{array}$ & 3 & 6 & 27 & 57 & 3 & 6 & 12 & 26 & 2 & 4 \\
\hline
\end{tabular}

\section{SUMMARY OF THE FINDINGS}

The purpose of the study was to assess of factors contributing to delayed surgeries in enlarged prostate patients at Kisumu County Referral Hospital. Specifically, the study sought to assess how the level of knowledge and awareness of prostate cancer contributes to delayed surgeries; to assess how institutional factors contribute to delayed surgeries and to assess how socio-economic factors contribute to delayed surgeries in enlarged prostate patients at Kisumu County Referral Hospital. The study adopted a descriptive survey research design with both qualitative and quantitative approaches and targeted all the enlarged prostate patients at the hospital under review from which exclusion and inclusion criteria were used to select a sample of 50 respondents to participate in the study. Data was collected from the respondents by the use of structured questionnaires after which the data was sorted and checked for validity before analysis was done.

During the data collection exercise, 50 questionnaires were issued to the respondents. Of the 50 questionnaires distributed, 47 were returned in time which gave a questionnaire return rate of $94 \%$. Study findings indicated that all the respondents were male thus legible for the study and that majority of the respondents, $40 \%$ had either informal education or had not received any education with $34 \%$ of the respondents reporting to have attained primary education.

The majority of the respondents, $45 \%$ were casual workers while only $17 \%$ reported being permanently employed. Findings also indicated that $45 \%$ of the respondents earned an income that range from 11,000 to 20,000 monthly. The majority of the respondents also reported that they were undertaking chemotherapy sessions while only $13 \%$ stated that they were doing follow-up after treatment sessions.

The major findings of the study based on the study objectives of the study are presented in the subsequent sub-sections of this section:

\section{Level of Knowledge and Awareness on Prostate Cancer}

The study findings indicated that the majority of the respondents, 91\%, had knowledge on prostate cancer with $83 \%$ stating that the medium through which they learned of the disease was the media, friends, and relatives and at the workplace. It emerged however that the majority of the respondents were not sure of often one should be screened for the disease. A majority $53 \%$ of the respondents stating that unwillingness to be screened for the disease was majorly due to lack of knowledge. It also emerged from the findings that it was generally perceived that prostate cancer kills anyone who gets it no matter when it is found and how it is treated with $62 \%$ of the respondents positively affirming this. Early sexual engagement, multiple sexual partners, poor diet, family history, lack of physical exercise and carbonated drinks were cited by the respondents as some of the predisposing factors to prostate cancer. 


\section{Institutional Factors Contributing to Delayed Surgeries}

Study findings indicated that the hospital was crowded, $78 \%$, and thus the available resources were not sufficient to cater for the population seeking medical attention while $66 \%$ of the respondents that general cleanliness and hygiene at the hospital was below the expected standards. Institutional factors related to doctors'/nurses' workmanship came up as the most common contributors to delayed surgeries and medical attention in terms of negligence, $66 \%$, poor communication channels hence conflicting information, $72 \%$, and doctors'/nurses' competence at work, $42 \%$. Accessibility to the hospital was also a major contributor, $81 \%$, and failure to strictly adhere to set appointments due to other more emergent cases, $66 \%$.

\section{Socio-economic Factors Contributing to Delayed Surgeries}

As pertains to the socio-economic factors study findings revealed that the family plays a major role in one's health decisions especially pertaining to chronic diseases such as cancer with $66 \%$ and that traditional beliefs, myths and perceptions may hinder ones intent to seek medical services (45\%). Evident from the research findings is that the economic status of an individual and lack of finances limits access to quality and timely healthcare with $83 \%$ and $87 \%$ of the respondents positively affirming these. It was also established that access to medical care may be limited by cultural beliefs with $63 \%$ of the respondents positively affirming this.

\section{CONCLUSION}

With regard to the findings of the study carried out at Kisumu County Referral Hospital, various conclusions can be drawn as pertains to the factors contributing to delayed surgeries in enlarged prostate patients.

First, the study established that even though most of the respondents had knowledge on prostate cancer, the intent to be screened for the disease is still low and hence most cases are diagnosed at advanced stages. It can thus be concluded, based on this, that the population around the area of study has not been fully mobilized and sensitized on the need to get screened for the disease to manage it, if found, at its early stages.

The study established that multiple institutional factors, both physical facilities and environment and matters of workmanship of the doctors and or nurses do contribute largely to delayed surgeries in enlarged prostate patients. It is on this basis that the study concludes the majority of the delays in surgeries in enlarged prostate patients at the hospital are due to the institution's inability in terms of resources, facilities and qualified and competent personnel.

A significant link was also established between socio-economic factors and delayed surgeries. The role of one's family, lack of finances and traditional beliefs have been identified and to be contributors to seek medical intervention. The study thus concludes that socio-economic factors do contribute to delayed surgeries in enlarged prostate patients at Kisumu County Referral Hospital.

\section{RECOMMENDATIONS}

The study sought to assess factors contributing to delayed surgeries in enlarged prostate patients at Kisumu County Referral Hospital. An analysis of the study findings was done and several conclusions have been drawn from the findings.

First, the study recommends that there should be mobilization and sensitization to create awareness and increase the knowledge of the general public on prostate cancer as pertains to matters of screening and treatment.

Secondly, the study recommends that the government, through the Ministry of Public Health and Sanitation and other key players in the health sector should find ways of improving the facilities, resources and staff as a measure to manage the everincreasing population seeking medical care at the hospital.

Moreover, the study recommends mitigation measures to help tradition beliefs, myths and cultures that may hinder access to medical care. A recommendation is also made to the government to find ways of reducing medical costs, especially for 
cancer patients, so as to enable victims' access to medical care with ease.

Finally, the study recommends further similar studies in other areas of the country for comparative purposes.

\section{ACKNOWLEDGEMENT}

We sincerely appreciate God for seeing us through the entire study. Secondly, to Madam Joyce Kenanu and Mr. Andrew Bii for all the support throughout the study period. To family and friends for their constant support and encouragement, we can never thank you enough.

\section{REFERENCES}

American Cancer Society, (2018). Cancer Facts \& Figures 2018. Atlanta, Ga: American

Cancer Society; 2018.

American Joint Committee on Cancer, (2010). Prostate. In: AJCC Cancer Staging Manual.

$7^{\text {th }}$ ed. New York, NY: Springer; 2010:457-464.

Berenson, R.A. \& Cassel C.K., (2009). Consumer driven health care may not be what

patients need-caveat emptor. JAMA, 301(3)

Cheuck, L., et al. (2018). USPSTF Guidelines on Prostate Cancer Screening. US Preventive Services Task Force.

Ferlay, J.M.E., Jemal, D.V.M., Bray, F., Center, M.M., Ward, E., Forman., \& D., et al. (2011). Global Cancer Statistics. Volume 61, Issue 2, CA: A: A cancer journal for clinicians/pages: 134 .

https://doi.org/10.3322/Caac.20107.

Glickman, S.W., Bagget, K. A., Krubert, C.G., Peterson, E.D., Schulman, K.A., (2007).

Promoting quality: The health care organization from a management perspective. International Journal of Quality Health Care, 19(6).

Government of Kenya, (2007). Kenya Vision 2030. Government Printers Press, Nairobi.
International Agency for Research on Cancer. Kenyan, Nothern America and European Statistics 2008. Available at httpp://globocan.iarc.fr.

International Agency for Research on Cancer (2018). Latest global cancer data: cancer burden rises to 18.1 million new cases and 9.6 million cancer deaths in 2018. IARC

Jemal, A., Center, M. M., DeSantis, C., \& Ward, E. M. (2010). Global patterns of cancer incidence and mortality rates and trends. Cancer Epidemiology and Prevention Biomarkers, 19(8), 1893-1907.

KEMRI (2006). Nairobi Cancer Registry. Nairobi: Kenya Medical Research Institute. (K. M. R. Institute o. Document Number)

Kothari C. R. (2004). Research Methodology, $2^{\text {nd }}$ edition, New Delhi: Vikas Publishing house Pvt. Ltd, New Delhi. Leadership and Organization Development Journal, 18(7): 346354.

Lodenyo MM, Otsyula BK, Downing R, Yakubu K, Miima M, Ifeyinwa O. (2016). Factors

affecting time of access of in-patient care at Webuye District hospital, Kenya. Afr J Prm Health Care Fam Med. 2016;8(1), a898. http://dx. doi.org/10.4102/phcfm. v8i1.898

Lozano, R; Mohsen, N, Kyle Foreman, Stephen Lim, Kenji Shibuya, Victor Aboyans, Jerry Abraham, Timothy Adair, Rakesh Aggarwal, Stephanie Y Ahn et al., (2012). Global and regional mortality from 235 causes of death for 20 age groups in 1990 and 2010: a systematic analysis for the Global Burden of Disease Study 2010, The Lancet, Volume 380, Issue 9859, 2012, Pages 2095-2128, ISSN 0140-6736, https://doi.org/10.1016/S0140-6736(12)617280.(https://www.sciencedirect.com/science/articl e/pii/S0140673612617280)

Mwanga.M. D, (2013). Factors Affecting Patient Satisfaction at Kenyatta National

Hospital; A case of Cancer Outpatient Clinic. An Unpublished Masters Thesis. University of Nairobi.

39 | This work is licensed under a Creative Commons Attribution 4.0 International License. 
Ministry of Public Health and Sanitation (2011). National Cancer Control Strategy 2011-2016. Retrieved 7th June, 2013, from http://www.ipcrc.net/pdfs/Kenya-NationalCancer-Control-strategy.pdf

Mugenda O.M., Mugenda A.G. (1999). Research Methods Qualitative and Quantitative approaches, Kenyatta University, Nairobi Act Press

Minja, D. M. (2017). Rethinking ethical leadership in Kenya: Adopting a new paradigm. The Journal of Values-Based Leadership, 10(1), 5.

National Cancer control strategy (2011-2016). Ministry of Health. Kenya.

Negoita S, Feuer EJ, Mariotto A, Cronin KA, Petkov VI, Hussey SK, Benard V, Henley SJ, Anderson RN, Fedewa S, Sherman RL, Kohler BA, Dearmon BJ, Lake AJ, Ma J, Richardson LC, Jemal A, Penberthy L. (2018). Annual Report to the Nation on the Status of Cancer, part II: Recent changes in prostate cancer trends and disease characteristics. Cancer. 2018 Jul 1;124(13):2801-2814. doi: 10.1002/cncr.31549. Epub 2018 May 22. PMID: 29786851; PMCID: PMC6005761.

Omondi, K.B., (2016). Factors influencing service delivery in public hospitals; a case of

Nairobi County, Kenya. An Unpublished Masters Thesis. University of Nairobi.

Oladepo, O., Akinola, Y., Yusuf, O. B., \& Arulogun, S.O. (2009). Prostate Cancer

Awareness, Knowledge and Screening Practices among older men in Oyo State, Nigeria. International Quarterly of Community Health Education

Oso, W. Y., \& Onen, W. (2008). A General Guide to Writing Research and Report. $2^{\text {nd }}$ edition, Makerere University, Kampala

Pinsky, P.F., Porok, P.C., \& Kramer, P.S. (2017). Prostate Cancer Screening- A Perspective of the Current State of the Evidence. $N$ Engl J Med
2017; 376:1285-1289. DOI: 10.1056/NEJMsb1616281.

Rashid, W.E.W., \& Jusoff, HJ.K. (2009). Service quality in health care setting. Int J Health Qual Assur. $\quad$ PMID: 19725368 DOI: 10.1108/09526860910975580.

Rebbeck, T. R., Devesa, S. S., Chang, B. L., Bunker, C. H., Cheng, I., Cooney, K., et al.

(2013). Global patterns of prostate cancer incidence, aggressiveness, and mortality in men of African descent. Prostate Cancer, 2013, 560857.

Saunders, M., Lewis, P., \& Thornhill, A. (2003). Research Methods for Business Students (3rd ed.). England: Prentice Hall.

Sekaran, U. (2006). Research Methods for Business, $4^{\text {th }}$ edition, John Wiley and Sons, Inc. New York

Sigrid, D. (2010). Prostate Cancer Screening with PSA Department and Urology Institute

of Clinical Sciences. The Sahlgrenska Academy ay Goteborg University, Sweden.

Orodho, A.J. (2003). Essentials of educational and social science research methods. Nairobi: misola publishers. Volume 54. Pages 71-82.

World Health Organization (2004). The global burden of disease: update. Geneva: World Health Organization, 2008.

40 | This work is licensed under a Creative Commons Attribution 4.0 International License. 